\title{
A produção de conhecimento em tempos de conflito: o lugar das Ciências Sociais
}

DoI

http://dx.doi.org/10.11606/ 2179-0892.ra.2018.145516

\section{Márcia Lima}

- Universidade de São Paulo / São Paulo, SP, Brasil

vrmrlima@usp.br

RESUMO

O artigo procura fornecer uma breve análise sobre os desafios colocados para os intelectuais das Ciências Sociais brasileiras tendo em vista o cenário conservador em curso no país. O texto identifica dois processos importantes e correlatos. O primeiro envolve a restrição econômica e o crescimento do conservadorismo no Congresso e no Executivo, enquanto o outro envolve os resultados das mudanças produzidas pela redução das desigualdades sociais e raciais que alteraram o cenário e os atores envolvidos nos espaços de produção de conhecimento.

Ciências sociais, raça, gênero, ações afirmativas 
Em primeiro lugar, eu gostaria de agradecer aos organizadores do Fórum Quem tem medo dos antropólogo(a)s? e deste dossiê pelo convite para participar deste diálogo tão premente às questões acadêmicas e políticas, que estão sempre entrelaçadas no processo de produção de pesquisa. A situação que a Associação Brasileira de Antropologia ( $A B A$ ) tem enfrentado neste embate político é resultado de uma longa história institucional e seu posicionamento no debate público. A atuação de suas comissões temáticas sempre trouxe muita visibilidade aos temas estudados, assim como tem contribuído tanto para a renovação quanto para a perenidade da agenda dos estudos da área.

O objetivo deste artigo é desenvolver um conjunto de ideias e argumentos, considerando as questões colocadas pelos colegas da Antropologia, procurando conectar tais questões à agenda de investigação das Ciências Sociais e à agenda política e social do estado brasileiro. Procurarei destacar os pontos que considero importantes para que possamos compreender e debater as ameaças e represálias que estão ocorrendo contra os intelectuais das Ciências Sociais e particularmente os episódios em torno da ABA, relatados neste dossiê. Marcarei minhas inquietações intelectuais como socióloga, mas, ao mesmo tempo, represento neste diálogo com a Associação Brasileira de Antropologia (ABA), a Sociedade Brasileira de Sociologia (SBS), sem ser sua porta-voz. Minhas reflexões aqui não representam uma fala da SBS, mas de uma associada'.

Meu argumento é que estamos enfrentando dois contextos políticos que se complementam. O primeiro envolve a restrição econômica e o crescimento do conservadorismo no Congresso e no Executivo e o outro envolve os resultados das mudanças produzidas pela tímida redução das desigualdades sociais e raciais, que alteraram o cenário e os atores envolvidos nos espaços de produção de conhecimento.

\section{O CONTEXTO ATUAL: UM CENÁRIO DE MÚLTIPLAS CRISES}

No Brasil atual é possível identificar uma série de ações e decisões governamentais que têm afetado a autonomia e o orçamento das pesquisas científicas no Brasil. De acordo com a Sociedade Brasileira para o Progresso da Ciência (SBPC), o orçamento de 2018 , 4,6 bilhões de reais, representa uma redução de $25 \%$ em relação ao orçamento de 2017. Se compararmos com o orçamento de 2013, que chegou a 8,4 bilhões, houve uma redução de $46 \%$ em cinco anos. Este corte é alarmante e coloca em risco a continuidade de projetos científicos, assim como, em algumas áreas, provoca a evasão de pesquisadores brasileiros para outros países².

Entretanto, as restrições não se limitam às questões orçamentárias. Os últimos ocupantes das pastas de Ciência e Tecnologia e da Educação, ministérios e secretarias que detêm recursos para investimento em pesquisa e formação, têm
1 Na ocasião do convite eu ocupava o cargo na diretoria da Sociedade Brasileira de Sociologia, cujo mandato encerrou-se em novembro de 2017.

2 Disponível em: http://portal.sbpcnet.org.br/ noticias/sbpc-alerta-novo-corteno-orcamento-vai-desmontarpesquisa-cientifica-no-brasil/. 
demonstrado que as restrições podem se tornar programáticas. Essa preocupação esteve presente quando, em 2015, no segundo mandato da presidenta Dilma Roussef, Aldo Rebelo tomou posse como ministro de Ciência e Tecnologia. A preocupação da comunidade científica deu-se por dois motivos. Primeiro porque foi uma escolha política e não técnica e, segundo, porque em 2010, o deputado foi relator do projeto de revisão do Código Florestal, Aldo Rebelo afirmou que ciência do aquecimento global era uma "doutrina de fé".

No caso da educação, desde o primeiro mandato da presidenta Dilma, alguns temas e questões estão sofrendo vetos tanto do congresso como da base aliada do governo. Alguns casos emblemáticos. Em 2011, houve o veto da presidenta à distribuição do kit anti-homofobia por pressão da bancada evangélica e da igreja católica. O momento mais dramático desse retrocesso foi o Plano $\mathrm{Na-}$ cional da Educação sancionado em 2016, que vetava toda e qualquer referência a gênero e sexualidade. Após o golpe, a situação se tornou mais dramática, com a continuidade dos cortes orçamentários e com o avanço dos movimentos conservadores como o Escola sem partido. Este movimento tem tentado influenciar o conteúdo programático da prática docente no ensino fundamental. Mais recentemente, neste ano de 2018, um colega da Universidade de Brasília sofreu uma tentativa de restrição de liberdade de cátedra, pelo próprio Ministério da Educação, diante de título de disciplina onde aparece a referência ao termo golpe. Em tempos de recursos escassos, a restrição orçamentária tem inviabilizado a permanência e/ou desenvolvimento de agendas que desagradam setores conservadores da sociedade.

Almeida analisou os discursos dos deputados federais na votação do impeachment no congresso nacional, momento de consolidação do golpe, e em discursos posteriores. Segundo Almeida, a maioria dos deputados federais que evocaram Deus são aqueles que atuam em pautas que defendem uma moralidade pública mais reguladora, uma economia menos estatizante e mais pró-mercado, assim como apoiam uma política de segurança mais repressiva e punitiva (Almeida, 2017: 78). Essa atuação parlamentar contribuiu de forma efetiva não apenas para o golpe como também para os retrocessos relatados acima. Embora a presidenta Dilma ainda no primeiro mandato já tenha recuado em pautas importantes em virtude da reeleição e das pressões da base aliada, o cenário se tornou mais dramático após o golpe.

\section{DE ONDE VEM ESTA REAÇÃO CONSERVADORA?}

Durante um curto período de tempo, o Brasil experimentou um conjunto de transformações importantes. Algumas delas associadas a mudanças de caráter estrutural e outras associadas às formas de enfrentamento das desigualdades e 
aos preconceitos sociais, raciais e de gênero.

Queda na taxa de fecundidade, inclusive entre os mais pobres, mudança nos arranjos familiares e alterações no padrão da População em Idade Ativa são alguns fatores demográficos em curso no Brasil que altera as dinâmicas das desigualdades. Já no campo econômico, a primeira década deste século foi marcada pelo crescimento econômico e seus efeitos significativos no mercado de trabalho como o aumento da formalização, da contribuição previdenciária, valorização do salário mínimo, além do aumento da escolaridade da força de trabalho. Todos esses aspectos contribuíram para uma mudança no cenário das desigualdades sem que houvesse políticas específicas.

Além dessas mudanças estruturais, um outro conjunto de políticas foram importantes para a construção de um cenário mais inclusivo. Políticas redistributivas, como o Programa Bolsa-Família, políticas afirmativas como a implantação das cotas sociais e raciais nas instituições de ensino superior. No que concerne à diminuição da pobreza, as políticas de transferência de renda foram fundamentais. Embora não exista nenhuma condicionalidade ou critério de cunho étnico-racial, uma expressiva porcentagem dos beneficiários é negra. Na base da pirâmide social, políticas sociais sem recorte racial foram eficazes para melhorar a situação da população negra. Já as políticas focais alteraram tanto as dinâmicas redistributivas quanto as dinâmicas de reconhecimento. As cotas raciais nas universidades federais e no Programa Universidade para Todos mudaram o perfil dos estudantes universitários. No campo do reconhecimento, a lei 10639, que propõe novas diretrizes curriculares para o estudo da história e cultura afro-brasileira e africana e o reconhecimento pelo STF da união homoafetiva são exemplos de mudanças recentes que modificaram a forma como o estado brasileiro lida com as questões sociais e das minorias e que foram recebidas de forma negativa por parte da população brasileira (Lima, 2010).

Há neste contexto duas especificidades que merecem destaque, uma mais ampla e outra mais específica. A mais ampla refere-se à modesta, mas impactante redução das desigualdades sociais, medida principalmente pelo Índice de Gini, que se baseia na renda ${ }^{3}$. Durante a primeira década deste século, o Brasil se destacou nacional e internacionalmente por esta redução. Entre 1976 e 1999, esse índice permaneceu em torno de 0,6, iniciando somente a partir dos anos 2000 uma trajetória de queda, que o trouxe o para 0,53 em 2010. Este patamar é ainda extremamente elevado quando comparado ao de países de nível de desenvolvimento econômico similar ao do Brasil (Comin, 2015: 369). Os efeitos desta redução foram amplamente estudados em diversas disciplinas, com especial destaque para as Ciências Humanas e Ciências Sociais Aplicadas, despertando o interesse internacional pelas transformações que estavam ocorrendo aqui e

3 O Índice de Gini é um do principais indicadores usado internacionalmente para medir o grau de concentração de renda. O índice varia de zero a um sendo que valor zero representa a situação de igualdade e o valor um representa o extremo oposto. 
dando mais destaque aos intelectuais deste campo.

A outra especificidade trata das transformações que tais políticas impulsionaram no ambiente universitário em particular, tanto para a docência quanto para a pesquisa. O público universitário vem mudando gradativamente com as políticas de acesso ao ensino superior. Jovens negros, trans, gays, passam a ocupar os bancos e a cena das universidades. As consequências desse processo não se resumem apenas na diversidade do corpo discente, mas também nas agendas de pesquisas que estão sendo redefinidas. Essa mudança tem formado alunos e pesquisadores que trazem outras experiências e olhares para dentro da academia. E, vale lembrar, que essas políticas de inclusão alteraram o perfil discente em todas as áreas de conhecimento e não apenas nas ciências humanas e sociais. Estão em todos os cursos, demandando novos temas, interesses distintos e muitas experiências a serem partilhadas.

Considerando esse debate de um ponto de vista sociológico, podemos concluir que o cenário mais estrutural dessas tensões envolve processos redistributivos ancorados em formas de reconhecimento. Políticas que redistribuem renda foram rejeitadas por uma parcela da população, mas como foram modestas e repercutiram no consumo das classes mais pobres, tornaram-se mais toleráveis. Por outro lado, quando falamos em redistribuir capital, a tensão se torna maior. O aumento do capital educacional dos mais pobres via políticas de acesso e expansão, assim como as modestas políticas de acesso à terra, tornaram-se elementos de forte tensão no processo redistributivo.

$A$ agenda de raça e gênero produziu uma reação conservadora violenta e o estado brasileiro, que até recentemente atuava como um agente que fomentava a discussão, se transformou num grande opositor à mesma. Esse deslocamento produziu tensões, recuos e frustrações que precisam ser enfrentadas.

\section{AS CIÊNCIAS SOCIAIS E A CONFLUÊNCIA DE TENSÕES: ATORES E SUJEITOS DA PESQUISA}

As transformações descritas acima produziram mudanças no papel e no lugar dos cientistas sociais junto ao estado e ao debate público. A interface entre produção acadêmica e implantação de políticas públicas ganhou outra dimensão e consequentemente maior visibilidade. Quando iniciamos nossa formação como cientistas sociais aprendemos a importância de desconstruir discursos prontos e saberes imediatos, utilizando a expressão de Pierre Bourdieu (2004). As percepções do outro investigado devem ser consideradas, percebidas, e assim damos sentido às experiências e construímos nossos conceitos. A nossa produção confronta diretamente as pré-noções e o senso comum, sendo muitas vezes rechaçada justamente por não corroborar os 
julgamentos de valores presentes na sociedade. Um exemplo marcante foi a implantação do bolsa família, que sempre sofreu fortes críticas como uma medida assistencialista, por seu baixo valor financeiro, a despeito de todas as análises de diferentes áreas, nacionais e internacionais, que apontavam para sua importância e eficácia.

No caso dos antropólogos, por exemplo, o tema dos remanescentes de quilombos e a produção de laudos para seu reconhecimento impactaram diretamente no acesso à terra. A realização de pesquisas de campo de longa duração, a convivência com os sujeitos da pesquisa, ou seja, o ol har que aprendemos e ensinamos nos nossos cursos e disciplinas produzem um conhecimento diferenciado sobre a complexidade das situações sociais. Esta característica está presente nas práticas etnográficas, mas não se restringe a elas. Os temas de gênero e sexualidade marcaram a atuação dos antropólogos no debate público, principalmente em virtude da violência contra as mulheres, a discussão sobre o aborto, assim como a homofobia presente no debate sobre os direitos civis da população LCBT e os inúmeros casos de violência contra este grupo.

A percepção da Ciência Política na análise das políticas públicas, do comportamento político eleitoral e das instituições democráticas, assim como a produção sociológica sobre desigualdades e estratificação social, dentre outros assuntos, constitui interpretações sobre o social que entram em disputa de legitimidade com outras áreas não acadêmicas. O tratamento dado a esses temas na academia muitas vezes entra em conflito com a gestão pública ou mesmo com atores da representação política que tomam decisões tendo em mente uma perspectiva eleitoral.

Considerando o atual cenário social, político e econômico, há um retrocesso em curso não apenas no campo dos direitos humanos básicos, mas também das condições sociais. Talvez seja necessário pensar numa discussão mais ampla com outros campos disciplinares, associações e organizações que têm enfrentado o mesmo problema. As divergências internas da comunidade científica-em especial sobre a temática da inclusão-precisam ser superadas em torno de uma agenda comum: o estado laico, o investimento em ciência e tecnologia como prioritário, assim como a importância da diversidade na produção de conhecimento.

Márcia Lima é professora do Departamento de Sociologia da Universidade de São Paulo. Pesquisadora sênior do Centro Brasileiro de Análise e Planejamento associada ao Centro de Estudos da Metrópole, projeto CEPID/FAPESP. 


\section{REFERÊNCIAS BIBLIOGRÁFICAS}

ALMEIDA, Ronaldo

2017 "Os deuses do parlamento". Novos Estudos CEBRAP.

São Paulo, número especial: 71-79.

BOURDIEU, Pierre

2004 Oofício do sociólogo. Rio de Janeiro, Editora Vozes.

COMIN, Alvaro

2015 "Desenvolvimento econômico e desigualdades no Brasil: 1960-2010".

In ARRETCHE, M. (org.). Trajetórias das desigualdades: como o Brasil mudou nos últimos cinquenta anos. São Paulo, Unesp. pp. 369-396.

LIMA, Márcia

2010 "Desigualdades raciais e políticas públicas: ações afirmativas no governo Lula". Novos Estudos CEBRAP, São Paulo, n. 87: 77-95. 


\section{ABSTRACT}

This article proposes to provide a brief analysis of the main challenges posed to the Brazilian social sciences due to the conservative political context. The text identifies two crucial and related processes. The first involves the economic restraint associated with the growth of conservatism in Congress and in the Executive power, and the other includes the results of the changes produced by the reduction of social and racial inequalities that altered the scenario and the actors involved in the spaces of production of knowledge.

Recebido em 18 de fevereiro de 2018. Aceito em 10 de março de 2018.

\section{KEYWORDS}

Social Sciences, Race, Cender, Affirmative Actions 